\title{
Dynamics of thematic activation in recognition testing
}

\author{
Daniel R. Kimball, William J. Muntean, and Troy A. Smith \\ University of Oklahoma, Norman, Oklahoma
}

\begin{abstract}
Two experiments investigated the effects of spreading semantic activation during a recognition test. In Experiment 1, activation spreading during testing from words that were thematic associates of unstudied critical words yielded a linear increase in false alarms to such critical words as the number of tested associates increased, regardless of whether the theme appeared during study or whether any thematic processing occurred during study at all. In Experiment 2, the number of tested associates was held constant, and false alarms to critical words from unstudied themes increased linearly with the strength of association between the critical word and its tested associates, consistent with predictions of spreading-activation theory. For studied themes, however, testing weaker or stronger associates yielded similar rates of such false alarms, contrary to spreading-activation theory. These results suggest that test-induced thematic priming is driven by spreading activation for unstudied themes but by thematic reactivation for studied themes.
\end{abstract}

Many theories of memory and cognition include as a central feature the spread of activation within a semantic network (see, e.g., Collins \& Loftus, 1975). Understanding how such spreading activation operates is thus of central importance to these theories. In this article, we examine the influence on episodic memory tasks of spreading semantic activation during both encoding and testing. A paradigm that is well suited to this purpose is the Deese/ Roediger-McDermott (DRM) paradigm (Deese, 1959; Roediger \& McDermott, 1995), in which participants study a list of words related to a theme - all strong semantic associates (e.g., mad, rage, hate) of an unstudied critical word (anger) - and subsequently exhibit false recall and recognition of the critical word (see Gallo, 2006, for a review). A leading account of this phenomenon, the activation/monitoring theory (Roediger, Watson, McDermott, \& Gallo, 2001), assumes that activation spreads automatically throughout a semantic network during study, converging on the unstudied critical word identified with the theme. The theory assumes that this strong studyinduced thematic activation of the critical word impairs subsequent monitoring decisions seeking to discriminate between internal and external sources of such activation.

More recently, a number of studies have investigated the assumption that semantic activation also spreads automatically to the critical word during testing of its associates. These studies have typically manipulated the number of associates of a critical word that are tested for recognition prior to testing of the critical word. Results to date have been mixed.

For studied themes, most experiments have failed to observe any test-induced thematic activation of the critical word (Anastasi, Avery, Sinclair, Weitz, \& Rhodes, as cited in Coane \& McBride, 2006; Coane \& McBride, 2006, Experiment 1; Dodd, Sheard, \& MacLeod, 2006; Marsh, McDermott, \& Roediger, 2004). Coane and McBride (Experiments 2 and 3 ) reported an exception to this pattern, however. Their results were partially consistent with spreading activation, in that critical-word false alarms (FAs) were higher when some associates were tested previously than when none were; but the results were also partially inconsistent with spreading activation, in that such FAs did not increase further with the testing of more associates (see also Marsh \& Dolan, 2007, who reported a similar pattern with speeded recognition). Coane and McBride offered two possible explanations for this lack of further increase in FAs: (1) an increase in the accuracy of source monitoring as more associates were tested, or (2) the surpassing of some threshold of test-induced thematic activation with the testing of just a few associates.

This pattern, with critical-word FAs increasing as a function of testing some rather than no associates but not as a function of testing more rather than fewer associates, has been more regularly observed for unstudied themesthat is, themes for which semantic associates of the critical word appeared for the first time during testing (Coane \& McBride, 2006, Experiments 2 and 3; Marsh \& Dolan, 2007; Marsh et al., 2004). In these studies, however, the influence of studied themes on test-induced thematic activation for unstudied themes was unclear, because words from unstudied themes were always tested among words related to studied themes. The pervasive thematicity of the stimuli at both study and test might have induced greater reliance on thematic information in all recognition decisions, leading to more reliance on thematic activation for unstudied themes than would have occurred otherwise.

D. R. Kimball, dkimball@ou.edu 
Alternatively, the presentation of words related to studied themes during testing might have facilitated the discrimination and rejection of words related to unstudied themes, including the critical word, thus blunting the test-induced thematic activation that would have occurred otherwise for unstudied themes. Both of these possibilities reflect the influence of monitoring processes on recognition decisions, rather than a simple spread of semantic activation.

Accordingly, a major purpose of Experiment 1 was to determine whether testing alone could induce thematic activation, even when no thematic information at all was encountered during study and thus no words related to studied themes were tested. We compared two conditions in which words from unstudied themes appeared as foils during testing before the critical word. In the thematictargets/thematic-foils condition, studied words and targets comprised theme-related words, except for a few unrelated buffer words; in the unrelated-targets/thematic-foils condition, only unrelated words appeared as studied words and targets. If the testing of studied themes affects monitoring processes, test-induced thematic priming of the critical word for unstudied themes should be differentially affected by the thematicity of the targets. Also, notably, the unrelated-targets/thematic-foils condition affords the purest assessment to date of test-induced thematic priming, raising the intriguing possibility that false memories can be created during testing alone simply by repeatedly probing a particular theme, even when no thematic information is studied.

A second purpose of Experiment 1 involved the testinduced thematic priming of the critical word for studied themes reported by Coane and McBride (2006, Experiments 2 and 3), an important finding given the surprising difficulty in obtaining test-induced thematic priming for studied themes in other studies. In fact, Coane and McBride themselves observed such priming for studied themes only in their last two experiments, not in their first experiment. They considered but did not test an explanation for this discrepancy that involved the thematicity of the foils. In their first experiment, foils were unrelated words, whereas in their later experiments, foils were from unstudied DRM themes. The authors noted that with unrelated foils, "participants could endorse as old any item that was thematically related to the studied items," but the inclusion of related foils "might have made the discrimination more difficult, especially as the test progressed" (Coane \& McBride, p. 1033). An alternative explanation is that testing related foils in addition to related targets may have induced participants to base their judgments more on the thematic information most recently activated during testing than on that activated during study, which would reduce FAs to critical words related to themes that had been studied but not previously tested.

To test the importance of foil thematicity in test-induced thematic priming for studied themes, we included a third condition in Experiment 1 in which foils were unrelated to any theme, so that the only thematically related test words were targets from studied themes (thematic-targets/ unrelated-foils condition), and compared the critical-word FA rate in this condition with that in the thematic-targets/ thematic-foils condition. We expected that if foil thematicity enhances test-induced thematic priming for studied themes, then we would observe such priming in the thematic-targets/thematic-foils condition but not in the thematic-targets/unrelated-foils condition.

\section{EXPERIMENT 1}

\section{Method}

Participants. Participants were 181 undergraduate students enrolled in introductory psychology at the University of Texas at

Table 1

Example of Study List for Experiments 1 and 2

\begin{tabular}{|c|c|c|c|c|}
\hline $\begin{array}{c}\text { Serial } \\
\text { Position }\end{array}$ & Word & $\begin{array}{c}\text { Critical } \\
\text { Word } \\
\text { of Theme }\end{array}$ & $\begin{array}{c}\text { Number } \\
\text { of Tested } \\
\text { Theme } \\
\text { Words } \\
\text { (Experiment 1) }\end{array}$ & $\begin{array}{c}\text { Strength } \\
\text { of Tested } \\
\text { Theme } \\
\text { Words } \\
\text { (Experiment 2) }\end{array}$ \\
\hline 1 & joy & - & - & - \\
\hline 2 & edge & - & - & - \\
\hline 3 & basket & FRUIT & 6 & Weak \\
\hline 4 & snore & SLEEP & 0 & 0 \\
\hline 5 & soccer & FOOT & 12 & Weak \\
\hline 6 & arm & FOOT & 12 & Weak \\
\hline 7 & salad & FRUIT & 6 & Weak \\
\hline 8 & nap & SLEEP & 0 & 0 \\
\hline 9 & cherry & FRUIT & 6 & Weak \\
\hline 10 & walk & FOOT & 12 & Weak \\
\hline 11 & citrus & FRUIT & 6 & Strong \\
\hline 12 & shoe & FOOT & 12 & Strong \\
\hline 13 & ankle & FOOT & 12 & Strong \\
\hline 14 & peace & SLEEP & 0 & 0 \\
\hline 15 & doze & SLEEP & 0 & 0 \\
\hline 16 & pear & FRUIT & 6 & Strong \\
\hline 17 & tired & SLEEP & 0 & 0 \\
\hline 18 & toe & FOOT & 12 & Strong \\
\hline 19 & orange & FRUIT & 6 & Weak \\
\hline 20 & snooze & SLEEP & 0 & 0 \\
\hline 21 & juice & FRUIT & 6 & Weak \\
\hline 22 & kiwi & FRUIT & 6 & Strong \\
\hline 23 & hand & FOOT & 12 & Strong \\
\hline 24 & vegetable & FRUIT & 6 & Strong \\
\hline 25 & drowsy & SLEEP & 0 & 0 \\
\hline 26 & boot & FOOT & 12 & Weak \\
\hline 27 & sandals & FOOT & 12 & Strong \\
\hline 28 & slumber & SLEEP & 0 & 0 \\
\hline 29 & berry & FRUIT & 6 & Strong \\
\hline 30 & kick & FOOT & 12 & Weak \\
\hline 31 & inch & FOOT & 12 & Strong \\
\hline 32 & banana & FRUIT & 6 & Strong \\
\hline 33 & bed & SLEEP & 0 & 0 \\
\hline 34 & yard & FOOT & 12 & Weak \\
\hline 35 & rest & SLEEP & 0 & 0 \\
\hline 36 & wake & SLEEP & 0 & 0 \\
\hline 37 & apple & FRUIT & 6 & Weak \\
\hline 38 & awake & SLEEP & 0 & 0 \\
\hline 39 & income & - & - & - \\
\hline 40 & object & - & - & - \\
\hline
\end{tabular}

Note-For the unrelated-targets/thematic-foils condition in Experiment 1, 36 unrelated words were studied in lieu of 36 theme-related words. Weak and strong refer to the six associates with weaker versus stronger backward associative strength (BAS) to the critical word. For any studied theme, both weak and strong associates were studied and are not separately identified in this table. When six associates were tested in Experiment 1, they were randomly selected without regard to BAS. 
Arlington, participating for partial course credit. Five participants failed to follow instructions and/or could not discriminate between studied and new words; they were excluded from all analyses.

Design. Target-foil thematicity was manipulated between subjects, with random assignment of 58,57 , and 61 participants to the unrelated-targets/thematic-foils, thematic-targets/unrelated-foils, and thematic-targets/thematic-foils conditions, respectively. The number of associates tested before the critical word $(0,6$, or 12$)$ and-except in the unrelated-targets/thematic-foils condition-the study status of particular themes (studied, unstudied) were manipulated within subjects.

Materials. Thematic stimuli were drawn from the 36 DRM lists in Stadler, Roediger, and McDermott (1999) and comprised the 12 words with the strongest backward associative strength (BAS) to each critical word (as reported by Roediger et al., 2001) that were also in the MRC Psycholinguistic Database (www.psy.uwa.edu.au/ MRCDataBase/uwa_mrc.htm). BAS is the probability of producing the critical word as the first word in an association task when cued with a list word. Unrelated control stimuli comprised 264 other words chosen from the same database to match the DRM words on several psycholinguistic variables.

The 36 DRM themes were randomly assigned anew for each participant to six sets of six themes - one set for each study-test trialand to within-subjects conditions (study status and number of tested associates) within each set. The study list for each trial comprised 40 words (see Table 1). Unrelated words appeared as the first and last two words in order to control for primacy and recency. In the thematic-targets/thematic-foils and thematic-targets/unrelated-foils conditions, the remaining 36 studied words were the 12 words from each of the three DRM themes assigned to be studied in that trial, as in Coane and McBride (2006). In the unrelated-targets/thematicfoils condition, participants instead studied 36 randomly selected, unrelated words. The 36 studied words were randomly ordered anew for each participant.

The test for each trial was a 50-word old-new recognition test. The composition of the first 36 words differed across thematicity conditions. As Table 2 illustrates, in the thematic-targets/ thematic-foils condition, the first 36 items comprised 18 studied associates ( 6 from one studied DRM theme and 12 from another) and 18 unstudied associates (6 from one unstudied DRM theme and 12 from another), all as in Coane and McBride (2006). This same 36-word test sequence was used for the thematic-targets/ unrelated-foils condition, except that the 18 unstudied associates were replaced with 18 unstudied, unrelated words; it was also used for the unrelated-targets/thematic-foils condition, except that the 18 studied associates were replaced with 18 studied, unrelated words. The last 14 items in all tests comprised the critical words from the 6 DRM themes assigned to that trial, the 2 primacy items, the 2 recency items, and 4 unstudied, unrelated words - all in random order.

Procedure. After receiving instructions, each participant began studying words in the first trial. Words appeared on a desktop computer at a rate of $3 \mathrm{sec}$ per word, with a $500-\mathrm{msec}$ interstimulus interval. After a 30-sec distractor task, participants began the test for that trial. Participants proceeded at their own pace, pressing the "O" and "W" keys to indicate old and new judgments, respectively. Participants repeated these tasks for all six trials.

\section{Results}

As shown in Table 3, endorsements of thematic associates were unaffected by the manipulated variables $(p \mathrm{~s}>$ .10), with one exception: FAs to associates from unstudied themes were higher in the unrelated-targets/thematic-foils condition than in the thematic-targets/thematic-foils condition $\left[F(1,117)=5.53, M S_{\mathrm{e}}=.03, p=.0204\right]$. As shown in Figure 1, this same effect occurred for FAs to critical
Table 2

Example of Test List for the Thematic-Targets/Thematic-Foils Condition in Experiment 1

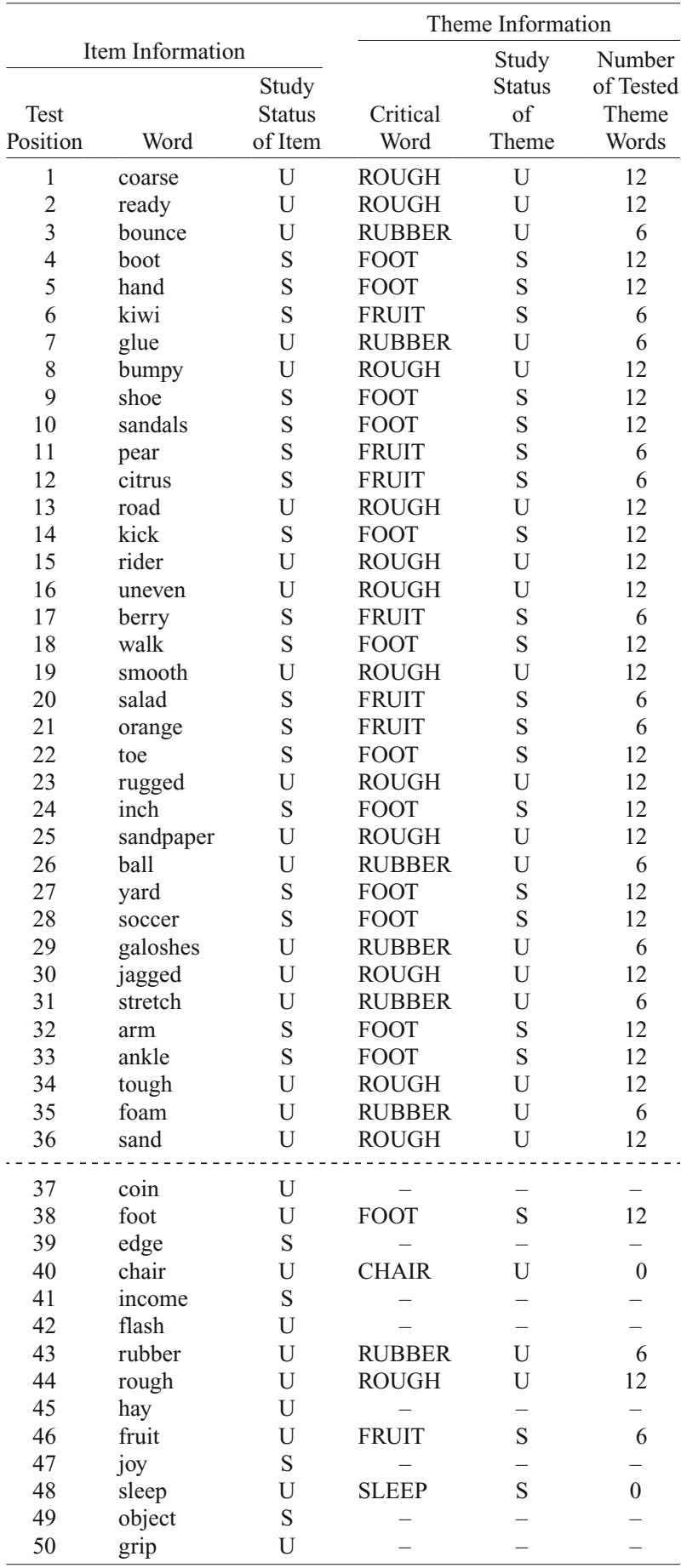

Note-S, studied; U, unstudied. The dashed line separates the sets of tested words that were separately randomized; all tested associates appeared in the first set, and all critical words appeared in the second set. The dashed line is included for illustration only; participants were not given any cue signaling this transition. For the thematic-targets/unrelatedfoils condition, the 18 theme-related foils in the first tested set were replaced with 18 unrelated foils. For the unrelated-targets/thematic-foils condition, the 18 theme-related targets in the first tested set were replaced with 18 unrelated targets. 
Table 3

Mean Endorsement Rates and Standard Errors for Noncritical Words in Experiment 1

\begin{tabular}{|c|c|c|c|}
\hline \multirow{3}{*}{$\begin{array}{c}\text { Item Study } \\
\text { Status }\end{array}$} & \multicolumn{2}{|c|}{ DRM Theme Words } & \\
\hline & $\begin{array}{c}6 \\
\text { Associates } \\
\text { Tested }\end{array}$ & $\begin{array}{c}12 \\
\text { Associates } \\
\text { Tested }\end{array}$ & $\begin{array}{c}\text { Unrelated } \\
\text { Words }\end{array}$ \\
\hline & $\overline{S E}$ & $\overline{S E}$ & $M$ \\
\hline
\end{tabular}

Thematic-Targets/Thematic-Foils Condition

\begin{tabular}{lcccccc} 
Studied (targets) & .81 & .02 & .80 & .02 & - & - \\
Unstudied (foils) & .11 & .02 & .12 & .02 & .12 & .02 \\
Unrelated-Targets/Thematic-Foils & Condition \\
Studied (targets) & - & - & - & - & .78 & .02 \\
Unstudied (foils) & .16 & .02 & .17 & .02 & .21 & .02 \\
Thematic-Targets/Unrelated-Foils Condition & \\
Studied (targets) & .79 & .02 & .81 & .02 & - & - \\
Unstudied (foils) & - & - & - & - & .15 & .02 \\
\hline
\end{tabular}

Note-DRM, Deese/Roediger-McDermott.

words from unstudied themes $\left[F(1,117)=8.91, M S_{\mathrm{e}}=\right.$ $.10, p=.0035]$.

Figure 1 also shows that - unlike in all other published findings to date-critical-word FAs increased linearly in all conditions as a function of the number of previously tested thematic associates. For studied themes, there was a reliably linear effect $[t(116)=4.02, p<.0001]$ and no reliable nonlinearity $(t<1)$; critical-word FAs were higher following testing of 6 associates than following testing of no associates $[t(116)=2.11, p=.0373]$, and they were higher following testing of 12 associates than following testing of 6 associates $[t(116)=2.22, p=.0283]$. For unstudied themes, similarly, there was reliable linearity $[t(117)=7.99, p<.0001]$ and no reliable nonlinearity $(t<1)$; again, critical-word FAs were higher following testing of 6 associates than following testing of no associates $[t(117)=3.94, p=.0001]$, and they were higher following testing of 12 associates than following testing of 6 associates $[t(117)=3.92, p=.0002]$. None of these effects interacted with target-foil thematicity $(p s>.25)$.

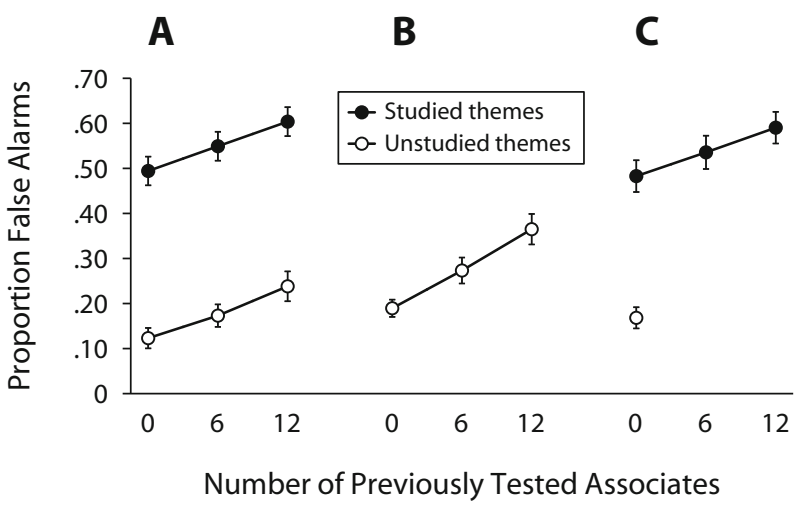

Figure 1. Mean proportions of false alarms to critical words (and standard errors) in Experiment 1 as a function of number of tested associates and theme study status for the thematictargets/thematic-foils (A), unrelated-targets/thematic-foils (B), and thematic-targets/unrelated-foils $(C)$ conditions.

\section{Discussion}

One novel finding was the occurrence of test-induced thematic priming of the critical word even when no thematic information at all had appeared during study - the purest demonstration to date that thematic priming can be induced by testing alone. A second novel - and unexpected-finding was the linear increase in critical-word FAs as a function of the number of previously tested associates in all conditions, contrary to the findings in previous studies that increasing the number of previously tested associates had no effect on such FAs, or an effect only for the testing of some associates versus none. The pervasiveness of this linear pattern across all conditions provided no support for any influence of target-foil thematicity on test-induced thematic priming.

Compared with previous findings, our pervasively linear pattern is more clearly consistent with a simple spread of semantic activation from thematic associates to the critical word during testing. One aspect of the results points to a role for monitoring processes as well, however: There was an overall decrease in endorsements of unstudied themerelated words - including both the critical word and its unstudied, tested associates - when they were tested in the context of studied words that were theme-related rather than unrelated. This finding suggests that words related to unstudied themes were easier to identify and reject overall when contrasted with words related to studied themes during testing. Nevertheless, the effect of spreading activation was still evident in the linear pattern of test-induced thematic priming.

\section{EXPERIMENT 2}

In Experiment 1, as in previous studies, two variables were confounded: An increase in the number of associates tested prior to the critical word was always accompanied by an increase in the total strength of association between those associates and the critical word. The linear pattern of test-induced thematic priming of the critical word could thus have been attributable to the frequency and/or magnitude of spreading activation. In Experiment 2, we unconfounded these variables by holding the number of previously tested associates constant while varying their total strength of association to the critical word, thus isolating the role of that strength in inducing thematic priming.

We are aware of only two previous studies that held the number of tested associates constant while varying their strength of association to the critical word. Fernandez, Diez, Alonso, and Beato (as cited in Marsh et al., 2004) reported that, for studied themes, critical-word FAs did not differ regardless of whether five weak associates, five strong associates, or no associates were tested; for unstudied themes, critical-word FAs did not differ for weak versus strong tested associates, but they were higher in each of those conditions than when no associates were tested. Gunter, Ivanko, and Bodner (2005) found no differences in FA rates or remember judgments for critical words when three weak versus three strong studied associates were tested. The results from these two studies thus failed to support a spreading-activation account that is based on 
strength of association. Reexamining this issue seemed appropriate given the novel linear pattern of critical-word FAs we observed in Experiment 1.

\section{Method}

Participants were 104 undergraduate students enrolled in introductory psychology at the University of Texas at Arlington, participating for partial course credit. Two participants were excluded from all analyses for failure to discriminate between studied and new words. The method was the same as that in the thematic-targets/ thematic-foils condition in Experiment 1, except that instead of manipulating the number of associates tested prior to a critical word, we held that number constant at 6 and instead manipulated the BAS from such associates to the critical word (see Table 4). Prior to test-

Table 4

Example of Test List for Experiment 2

\begin{tabular}{|c|c|c|c|c|c|}
\hline \multirow{2}{*}{\multicolumn{3}{|c|}{ Item Information }} & \multicolumn{3}{|c|}{ Theme Information } \\
\hline & & & \multirow[b]{2}{*}{$\begin{array}{l}\text { Critical } \\
\text { Word }\end{array}$} & \multirow{2}{*}{$\begin{array}{l}\text { Study } \\
\text { Status } \\
\text { of } \\
\text { Theme }\end{array}$} & \multirow{2}{*}{$\begin{array}{c}\text { Strength } \\
\text { of Tested } \\
\text { Theme } \\
\text { Words }\end{array}$} \\
\hline $\begin{array}{c}\text { Test } \\
\text { Position }\end{array}$ & Word & $\begin{array}{c}\text { Study } \\
\text { Status } \\
\text { of Item }\end{array}$ & & & \\
\hline 1 & orange & $\mathrm{S}$ & FRUIT & $\mathrm{S}$ & Weak \\
\hline 2 & cherry & $\mathrm{S}$ & FRUIT & $\mathrm{S}$ & Weak \\
\hline 3 & bounce & $\mathrm{U}$ & RUBBER & $\mathrm{U}$ & Weak \\
\hline 4 & apple & $\mathrm{S}$ & FRUIT & $\mathrm{S}$ & Weak \\
\hline 5 & toe & $\mathrm{S}$ & FOOT & $\mathrm{S}$ & Strong \\
\hline 6 & sandpaper & $\mathrm{U}$ & ROUGH & $\mathrm{U}$ & Strong \\
\hline 7 & ball & U & RUBBER & $\mathrm{U}$ & Weak \\
\hline 8 & inch & $\mathrm{S}$ & FOOT & $\mathrm{S}$ & Strong \\
\hline 9 & ankle & $\mathrm{S}$ & FOOT & $\mathrm{S}$ & Strong \\
\hline 10 & smooth & U & ROUGH & U & Strong \\
\hline 11 & coarse & $\mathrm{U}$ & ROUGH & $\mathrm{U}$ & Strong \\
\hline 12 & spring & $\mathrm{U}$ & RUBBER & $\mathrm{U}$ & Weak \\
\hline 13 & sole & U & RUBBER & $\mathrm{U}$ & Weak \\
\hline 14 & tough & $\mathrm{U}$ & ROUGH & $\mathrm{U}$ & Strong \\
\hline 15 & rugged & $\mathrm{U}$ & ROUGH & U & Strong \\
\hline 16 & basket & $\mathrm{S}$ & FRUIT & $\mathrm{S}$ & Weak \\
\hline 17 & glue & $\mathrm{U}$ & RUBBER & $\mathrm{U}$ & Weak \\
\hline 18 & shoe & $\mathrm{S}$ & FOOT & $\mathrm{S}$ & Strong \\
\hline 19 & sandals & $\mathrm{S}$ & FOOT & $\mathrm{S}$ & Strong \\
\hline 20 & hand & $\mathrm{S}$ & FOOT & $\mathrm{S}$ & Strong \\
\hline 21 & juice & $\mathrm{S}$ & FRUIT & $\mathrm{S}$ & Weak \\
\hline 22 & stretch & U & RUBBER & $\mathrm{U}$ & Weak \\
\hline 23 & salad & $\mathrm{S}$ & FRUIT & $\mathrm{S}$ & Weak \\
\hline 24 & bumpy & $\mathrm{U}$ & ROUGH & $\mathrm{U}$ & Strong \\
\hline 25 & coin & U & - & - & - \\
\hline 26 & foot & U & FOOT & $\mathrm{S}$ & Strong \\
\hline 27 & edge & $\mathrm{S}$ & - & - & - \\
\hline 28 & chair & U & CHAIR & U & 0 \\
\hline 29 & income & $\mathrm{S}$ & - & - & - \\
\hline 30 & flash & U & - & - & - \\
\hline 31 & rubber & U & RUBBER & U & Weak \\
\hline 32 & rough & $\mathrm{U}$ & ROUGH & U & Strong \\
\hline 33 & hay & U & - & - & - \\
\hline 34 & fruit & U & FRUIT & $\mathrm{S}$ & Weak \\
\hline 35 & joy & $\mathrm{S}$ & - & - & - \\
\hline 36 & sleep & U & SLEEP & $\mathrm{S}$ & 0 \\
\hline 37 & object & $\mathrm{S}$ & - & - & - \\
\hline 38 & grip & U & - & - & - \\
\hline
\end{tabular}

Note-S, studied; U, unstudied. Weak and strong refer to the six associates with weaker versus stronger backward association strength to the critical word. The dashed line separates the sets of tested words that were separately randomized; all tested associates appeared in the first set, and all critical words appeared in the second set. The dashed line is included for illustration only; participants were not given any cue signaling this transition.

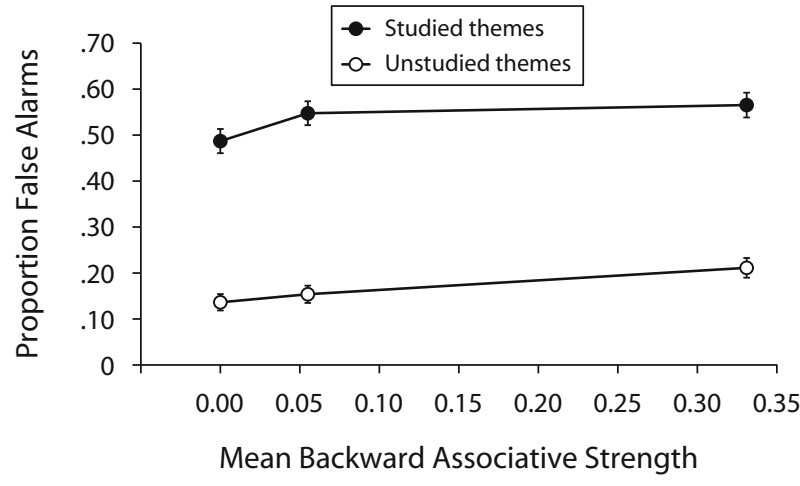

Figure 2. Mean proportions of false alarms to critical words (and standard errors) in Experiment 2 as a function of theme study status and backward associative strength of tested associates.

ing a critical word, therefore, we tested either (1) none of its associates or (2) the 6 weaker or 6 stronger associates from among the 12 associates for each DRM theme. This change shortened the test from 50 to 38 items. As in Experiment 1, we randomly assigned DRM themes to within-subjects conditions - theme study status and BAS in this experiment. On the basis of statistics reported in Roediger et al. (2001), the mean BAS probabilities across the 36 DRM lists were .055 and .331 for the 6 weaker and 6 stronger associates in each list, respectively. The study sequence for each trial was as illustrated in Table 1; random ordering at study avoided confounding BAS with study order.

\section{Results}

Figure 2 depicts the critical-word FA rates as a function of theme study status and mean BAS. Rates in the zero-associate conditions varied little from those in the thematic-targets/thematic-foils condition in Experiment 1, as did the rates for the six-associate conditions, collapsing across BAS. For unstudied themes, an unequal-interval trend analysis revealed a reliably linear pattern of criticalword FAs as a function of BAS, treated as a quantitative variable $[t(101)=3.52, p=.0006]$, and no reliable nonlinearity $(t<1)$; critical-word FAs were more frequent following testing of stronger associates than following testing of either no associates $[t(101)=3.40, p=.0010]$ or weaker associates $[t(101)=2.79, p=.0064]$, but they did not differ in the last two conditions $(t<1)$. For studied themes, although the linear trend was reliable $[t(101)=$ $2.57, p<.05]$, so was the nonlinear trend $[t(101)=2.24$, $p<.05]$; critical-word FA rates were higher when stronger or weaker associates were tested than when no associates were tested [stronger, $t(101)=3.23, p=.0017$; weaker, $t(101)=2.67, p=.0088]$ but did not differ between stronger and weaker tested associates $(t<1)$ (see Table 5). Our results were thus consistent with those Gunter et al. (2005) reported, but they contradicted key aspects of those Fernandez et al. (as cited in Marsh et al., 2004) reported.

\section{Discussion}

The results from Experiment 2 suggest a more complex relationship between tested associates' BAS and criticalword FAs than was suggested by the Experiment 1 results. For unstudied themes - that is, themes encountered for 
Table 5

Mean Endorsement Rates and Standard Errors for Noncritical DRM Theme Words in Experiment 2

\begin{tabular}{cccccc}
\hline & \multicolumn{3}{c}{ Backward Associative Strength } \\
\cline { 2 - 3 } \cline { 2 - 5 } & \multicolumn{2}{c}{ Weak } & & \multicolumn{2}{c}{ Strong } \\
\cline { 2 - 5 } \cline { 5 - 6 } & $M$ & $S E$ & & $M$ & $S E$ \\
\hline Studied (targets) & .82 & .01 & & .85 & .01 \\
Unstudied (foils) & .12 & .01 & & .10 & .01 \\
\hline
\end{tabular}

Note-DRM, Deese/Roediger-McDermott.

the first time during testing - the linear pattern of results remained consistent with a simple spread of activation during testing, on the basis of strength of association. For studied themes, however, reexposing even the weaker associates during testing increased critical-word FAs above baseline to an extent similar to that of reexposing stronger associates, yielding a nonlinear relationship between the tested associates' BAS and critical-word FAs. This pattern is consistent with a reminding or reinstatement of studyinduced thematic activation with the testing of some studied associates, be they weaker or stronger associates (for a similar argument, see Meade, Watson, Balota, \& Roediger, 2007, discussed further in the General Discussion). By virtue of having been studied in the thematic context during study, the weaker associates acquired a capacity to induce thematic activation during testing that was greater than would be commensurate with their strength of association to the critical word alone. These results thus suggest that thematic information encoded during study plays a role in test-induced thematic priming that is distinguishable from the role of strength-based spreading activation during testing.

\section{GENERAL DISCUSSION}

Given the importance of spreading-activation mechanisms in theories of memory and cognition, our findings provide important - and surprisingly rare - support for the straightforward prediction that thematic priming can occur for studied and unstudied themes alike through a spread of semantic activation during testing, much as it does during study. The novel findings in Experiment 1 - a pervasively linear relationship between the number of previously tested associates and critical-word FAs, even in the absence of any thematic processing during study - provide the clearest evidence to date of the thematic effects of such test-based spreading activation. We also observed a linear relationship in Experiment 2-for unstudied but not studied themes - between the tested associates' total strength of association to the critical word and criticalword FAs, consistent with a central role for such strength in test-based thematic priming, independent of any role for the number of tested associates. This finding suggests a parallel with the effect of the total associative strength of studied associates, which is thought to underlie the thematic effects of spreading activation during study (Robinson \& Roediger, 1997; Roediger et al., 2001; note, however, that the studied associates' total associative strength was confounded with the number of studied associates by Robinson \& Roediger, and with specific list effects by Roediger et al.).

For studied themes, the picture is more complex. The critical-word results from Experiment 2 suggest that a studied theme can be reactivated by testing even weak associates that were encountered in the thematic context during study. Consistent with this suggestion, Meade et al. (2007) hypothesized that on a direct memory task such as recognition, testing a word related to a studied theme induces a reactivation of the thematic associative structure that was activated during study, with this thematic structure being more resistant to decay than is activation resulting from automatic semantic priming in an indirect memory task such as lexical decision. Such a thematic associative structure seems quite similar theoretically to the gist trace posited by the fuzzy-trace theory, including its assumed resistance to decay (Brainerd \& Reyna, 2005), thus blurring any distinction between activation/monitoring and fuzzytrace theories - the two leading accounts of false recognition. Fuzzy-trace theory assumes that gist and verbatim traces form during study as a consequence of processing semantic and contextual detail, respectively; that studying a critical word's strong semantic associates creates a gist trace comprising thematic information strongly associated to the critical word; and that the gist trace is more robust over time than is the verbatim trace, leading to false recall and recognition of the critical word. The nonlinear effect of tested associates' strength on critical-word FAs for studied themes in Experiment 2 is thus consistent with renewed access to a thematic associative structure or gist trace activated or formed during study.

Nevertheless, an account that is based solely on renewed access to study-induced thematic activation is not sufficient to explain the increase in critical-word FAs in Experiment 1 when 12 rather than 6 associates were tested before the critical word. This increase suggests additional test-induced thematic priming beyond mere reactivation of a study-based thematic structure or gist trace. A possible interpretation of the patterns across both experiments is that when information related to a theme has been encountered during study, test-induced priming of the theme is a function of the frequency with which that theme is primed during testing, rather than a function of the total associative strength between the tested associates and the critical word. Of course, this interpretation requires more direct support.

We conclude by returning to our original hypotheses for Experiment 1 - that foil and/or target thematicity would influence the pattern of test-induced thematic priming. Although these hypotheses were not supported in the present study, future research could vary the proportion of foils and targets related to a given theme, thus varying the degree to which theme-related information encountered during testing is consistent with the theme's appearance during study. For example, the tested words related to a studied theme might be all targets (as in this study), all foils, or some combination of targets and foils. The degree of such consistency may induce differences in monitoring 
that may further modulate the linearity of the thematic priming effects reported here.

\section{AUTHOR NOTE}

This research was funded by Grant MH079357 from the National Institute of Mental Health to D.R.K. Correspondence concerning this article should be addressed to D. R. Kimball, Department of Psychology, University of Oklahoma, Dale Hall Tower, Room 705, 455 West Lindsey Street, Norman, OK 73019 (e-mail: dkimball@ou.edu).

\section{REFERENCES}

Brainerd, C. J., \& Reyna, V. F. (2005). The science of false memory. New York: Oxford University Press. doi:10.1093/acprof:oso/ 9780195154054.001.0001

CoAne, J. H., \& McBride, D. M. (2006). The role of test structure in creating false memories. Memory \& Cognition, 34, 1026-1036.

Collins, A. M., \& Loftus, E. F. (1975). A spreading-activation theory of semantic memory. Psychological Review, 82, 407-428. doi: $10.1037 / 0033-295 X .82 .6 .407$

DeESE, J. (1959). Influence of inter-item associative strength upon immediate free recall. Psychological Reports, 5, 305-312.

Dodd, M. D., Sheard, E. D., \& MacLeod, C. M. (2006). Re-exposure to studied items at test does not influence false recognition. Memory, 14, 115-126. doi:10.1080/09658210444000575

Gallo, D. A. (2006). Associative illusions of memory: False memory research in DRM and related tasks. New York: Psychology Press.
Gunter, R. W., Ivanko, S. L., \& Bodner, G. E. (2005). Can test list context manipulations improve recognition accuracy in the DRM paradigm? Memory, 13, 862-873. doi:10.1080/09658210444000458

Marsh, E. J., \& Dolan, P. O. (2007). Test-induced priming of false memories. Psychonomic Bulletin \& Review, 14, 479-483.

Marsh, E. J., McDermott, K. B., \& Roediger, H. L., III (2004). Does test-induced priming play a role in the creation of false memories? Memory, 12, 44-55. doi:10.1080/09658210244000405

Meade, M. L., Watson, J. M., Balota, D. A., \& Roediger, H. L., III (2007). The roles of spreading activation and retrieval mode in producing false recognition in the DRM paradigm. Journal of Memory \& Language, 56, 305-320. doi:10.1016/j.jml.2006.07.007

Robinson, K. J., \& RoEdiger, H. L., III (1997). Associative processes in false recall and false recognition. Psychological Science, 8, 231-237. doi:10.1111/j.1467-9280.1997.tb00417.x

Roediger, H. L., III, \& McDermott, K. B. (1995). Creating false memories: Remembering words not presented in lists. Journal of Experimental Psychology: Learning, Memory, \& Cognition, 21, 803-814. doi:10.1037/0278-7393.21.4.803

Roediger, H. L., III, Watson, J. M., McDermott, K. B., \& Gallo, D. A. (2001). Factors that determine false recall: A multiple regression analysis. Psychonomic Bulletin \& Review, 8, 385-407.

Stadler, M. A., Roediger, H. L., III, \& McDermott, K. B. (1999). Norms for word lists that create false memories. Memory \& Cognition, 27, 494-500.

(Manuscript received October 9, 2008; revision accepted for publication December 29, 2009.) 